\title{
Culture of spermatogonial stem cells and use of surrogate sires as a breeding technology to propagate superior genetics in livestock production: A systematic review
}

\author{
Wilkister Nakami ${ }^{1,2,3}$, Ambrose Ng'eno Kipyegon $^{1}$, James Nguhiu-Mwangi ${ }^{1}$, Christian Tiambo ${ }^{2,3}$ and Stephen Kemp ${ }^{2,3}$
}

1. Department of Clinical Studies, Faculty of Veterinary Medicine, University of Nairobi, 29053-00625 Nairobi, Kenya;

2. Livestock Genetics Program International Livestock Research Institute, 30709-00100, Nairobi, Kenya; 3. Centre for Tropical Livestock Genetics and Health (CTLGH)-ILRI, 30709-00100, Nairobi, Kenya.

Corresponding author: Wilkister Nakami, e-mail: wilkisterkelly@gmail.com

Co-authors: ANK: kipyegon@uonbi.ac.ke, JNM: jnmwangi@uonbi.ac.ke, CT: c.tiambo@cgiar.org, SK: s.kemp@cgiar.org Received: 04-08-2021, Accepted: 15-11-2021, Published online: 31-12-2021

doi: www.doi.org/10.14202/vetworld.2021.3235-3248 How to cite this article: Nakami W, Kipyegon AN, Nguhiu-Mwangi J, Tiambo C, Kemp S (2021) Culture of spermatogonial stem cells and use of surrogate sires as a breeding technology to propagate superior genetics in livestock production: A systematic review, Veterinary World, 14(12): 3235-3248.

\begin{abstract}
Background and Aim: Spermatogonial stem cells (SSCs) have previously been isolated from animals' testes, cultured in vitro, and successfully transplanted into compatible recipients. The SSC unique characteristic has potential for exploitation as a reproductive tool and this can be achieved through SSC intratesticular transplantation to surrogate sires. Here, we aimed at comprehensively analyzing published data on in vitro maintenance of SSC isolated from the testes of livestock animals and their applications.
\end{abstract}

Materials and Methods: The literature search was performed in PubMed, Science Direct, and Google Scholar electronic databases. Data screening was conducted using Rayyan Intelligent Systematic Review software (https://www.rayyan.ai/). Duplicate papers were excluded from the study. Abstracts were read and relevant full papers were reviewed for data extraction.

Results: From a total of 4786 full papers screened, data were extracted from 93 relevant papers. Of these, eight papers reported on long-term culture conditions ( $>1$ month) for SSC in different livestock species, 22 papers on short-term cultures (5-15 days), 10 papers on transfection protocols, 18 papers on transplantation using different methods of preparation of livestock recipients, and five papers on donor-derived spermatogenesis.

Conclusion: Optimization of SSC long-term culture systems has renewed the possibilities of utilization of these cells in gene-editing technologies to develop transgenic animals. Further, the development of genetically deficient recipients in the endogenous germline layer lends to a future possibility for the utilization of germ cell transplantation in livestock systems.

Keywords: culture, donor-derived spermatogenesis, marker, spermatogonial stem cells, transfection, transplantation.

\section{Introduction}

Spermatogenesis is the process through which spermatozoa are produced in males. The process is highly specialized and is dependent on the continuous actions of spermatogonial stem cells (SSCs). An equilibrium between self-renewal of SSC and the production of differentiating spermatogonia is key to sustaining optimal sperm production while preventing exhaustion of the stem cell reservoir. Regulation of SSC fate is partly influenced by signaling from growth factors which are synthesized by the somatic stem cell niche support cells, most importantly Sertoli cells [1,2]. SSCs have a unique potential to expand in vitro and form colonies of undifferentiated spermatogonia. These in vitro cultured SSCs when transplanted to testes of live recipient animals reestablish spermatogenesis producing

Copyright: Nakami, et al. Open Access. This article is distributed under the terms of the Creative Commons Attribution 4.0 International License (http://creativecommons.org/licenses/ by/4.0/), which permits unrestricted use, distribution, and reproduction in any medium, provided you give appropriate credit to the original author(s) and the source, provide a link to the Creative Commons license, and indicate if changes were made. The Creative Commons Public Domain Dedication waiver (http:// creativecommons.org/publicdomain/zero/1.0/) applies to the data made available in this article, unless otherwise stated. sperms of donor-derived haplotype [3]. The use of SSC to form gametes from specific sires provides an opportunity for genetic improvement in livestock. However, successful transplantation of SSC requires the establishment of robust and effective in vitro culture systems. Such a system will ensure that the small number of SSC $(0.03 \%$ of total testicular cells) isolated from the testes can be expanded to millions before transplantation [1]. Lack of methodologies for long-term expansion of SSC in culture and effective methods for the preparation of ideal recipients for transplantation of donor SSC has limited exploitation of SSC transplantation as an alternative breeding technology in livestock production systems [3]. Limited studies have documented protocols for long-term expansion of SSC in livestock species with varying success [3-6]. The ultimate proof of the existence of SSC in a culture dish is through transplantation and reestablishment of donor-derived spermatogenesis in the testes of the recipient animal [7]. In addition, successful culture systems of livestock species SSC will herald opportunities to study gene functions and explore gene editing methodologies for the in vitro cultured SSC.

Here, we aimed at collating data on in vitro culture systems of spermatogonial stems cells in 
livestock, specific SSC markers for identification, and gene manipulation of these cells. Thereafter, to document the standardized, workable, and reproducible in vitro culture conditions and feasible applications of SSC in livestock production systems.

\section{Materials and Methods}

\section{Ethical approval}

No experiments were conducted on live animals in this study, so ethical approval was unnecessary.

\section{Data sources and search strategy}

In line with Preferred Reporting Items for Systematic reviews and Meta-Analyses guidelines [8], a systematic literature search was performed. Searches were conducted in multiple electronic databases: PubMed, ScienceDirect, and Google Scholar for research articles published between January 1990 and February 2021. An initial and subsequent keyword searches with various combinations of search terms such as SSC terminologies, culture, and livestock species were undertaken. Keywords and subject terms included: ("spermatogonial stem cells") OR ("undifferentiated spermatogonia") OR ("male germline stem cells") OR ("spermatogonial stem cell transplantation") OR ("donor-derived spermatogenesis" OR ("spermatogonial stem cell transfection") AND ("culture") AND ("livestock") OR ("cattle") OR ("SHEEP") OR ("goats") OR ("Bovine") OR ("Pigs") OR ("camels").

\section{Selection criteria and data extraction}

Articles were included if they comprised original research published in a peer-reviewed journal and reported on the culture of spermatogonia cells in at least one livestock species. We excluded articles if; (i) articles were in non-English language, (ii) studies of spermatogonia stem cells in were non-livestock species, (iii) abstracts were not published as a full manuscript, and (iv) non-experimental studies. Article searches and screening were performed by considering article titles and abstracts for inclusion according to the search criteria. Data extraction from studies was performed by one author (WNN) and independently checked by another author (ANK) using a customized checklist. All the articles from the three electronic databases were exported to the Mendeley reference manager. Duplicate articles were excluded and the resultant data file from each of the databases was exported to Rayyan systematic reviews software (https://www.rayyan.ai/) [9] for screening.

\section{Statistical analysis}

For all the included studies, we categorized $\mathrm{SSC}$ in vitro culture systems into the following groupings: (i) Studies on in vitro culture of SSC for short-term $\leq 21$ days or long-term culture $\geq 21$ days; (ii) studies on SSC characterization using specific SSC and general pluripotent markers; (iii) studies on SSC transplantation, methods of recipient preparation, and fate of donor SSC; and (iv) studies on SSC gene manipulation methodologies. The quality of articles included in the review was accessed using the Cochrane handbook for systematic reviews version 6.2. Cochrane, 2021 (Available from www.training.cochrane.org/handbook). Each article was evaluated based on methodological study design and grouped according to the following categories: (i) Good quality studies; methodology as clear and precise mainly on multiparameter enrichment procedures for SSC, confirmation of SSC markers through real-time polymerase chain reaction and immunochemistry and SSC transplantation and (ii) medium quality: Clear methodology on isolation, enrichment, and characterization of SSC through immunostaining only.

\section{Results}

\section{Description of included studies}

Of the 4786 articles retrieved, 162 studies were reviewed (Figure-1); and 93 studies met all inclusion criteria. The 93 studies were geographically diverse and included 13 countries. Geographical distribution was follows: Iran $n=19$, the USA $n=17$, China $n=15$, Australia $n=14$, Korea $n=6$, Japan $n=1$, the United Arab Emirates $n=1$, India $n=6$, Brazil $n=3$, Canada $n=4$, the Netherlands $n=5$, Finland $\mathrm{n}=1$, and Switzerland $\mathrm{n}=1$. There was no study associated with SSCs in any species in Africa. Thirtysix studies focused on in vitro culture of SSC, 21 studies on identification of specific markers of SSC, 23 studies on transplantation of SSC, six studies on transfection, and five studies on donor-derived spermatogenesis. Categorization of studies based on the livestock species in which the study was conducted was as follows: Bovine $n=36$, goats $n=23$, pigs $n=17$, sheep $n=16$, and camels $n=1$. Record on the year of publication of the studies was as follows: the Year 2016-2021, $\mathrm{n}=28$ studies; the year 2005-2015, $\mathrm{n}=50$; and year 1990-2004, $\mathrm{n}=14$. The in vitro culture of SSC from livestock animals was first published in 1999. The early studies focused mainly on the isolation of a mixed germ cell population, including SSC and short-term culture of the cells [10-13]. Since then, there have been striking advances in the standardization of protocols for isolation, purification, characterization, and culture of SSC. Furthermore, the SSC transplantation technology has been explored for its viability in the production and dissemination of superior male gametes in livestock production systems. The synthesis of the data was qualitative and can be found in the subheadings below.

\section{Long-term culture of SSC and the in vitro culture conditions required}

The duration of which SSCs were maintained in culture was categorized into three: Culture for 1-3 days $(\mathrm{n}=8)$, culture 5-18 days $n=23$, and $>21$ days $n=7$. Of much interest was the 


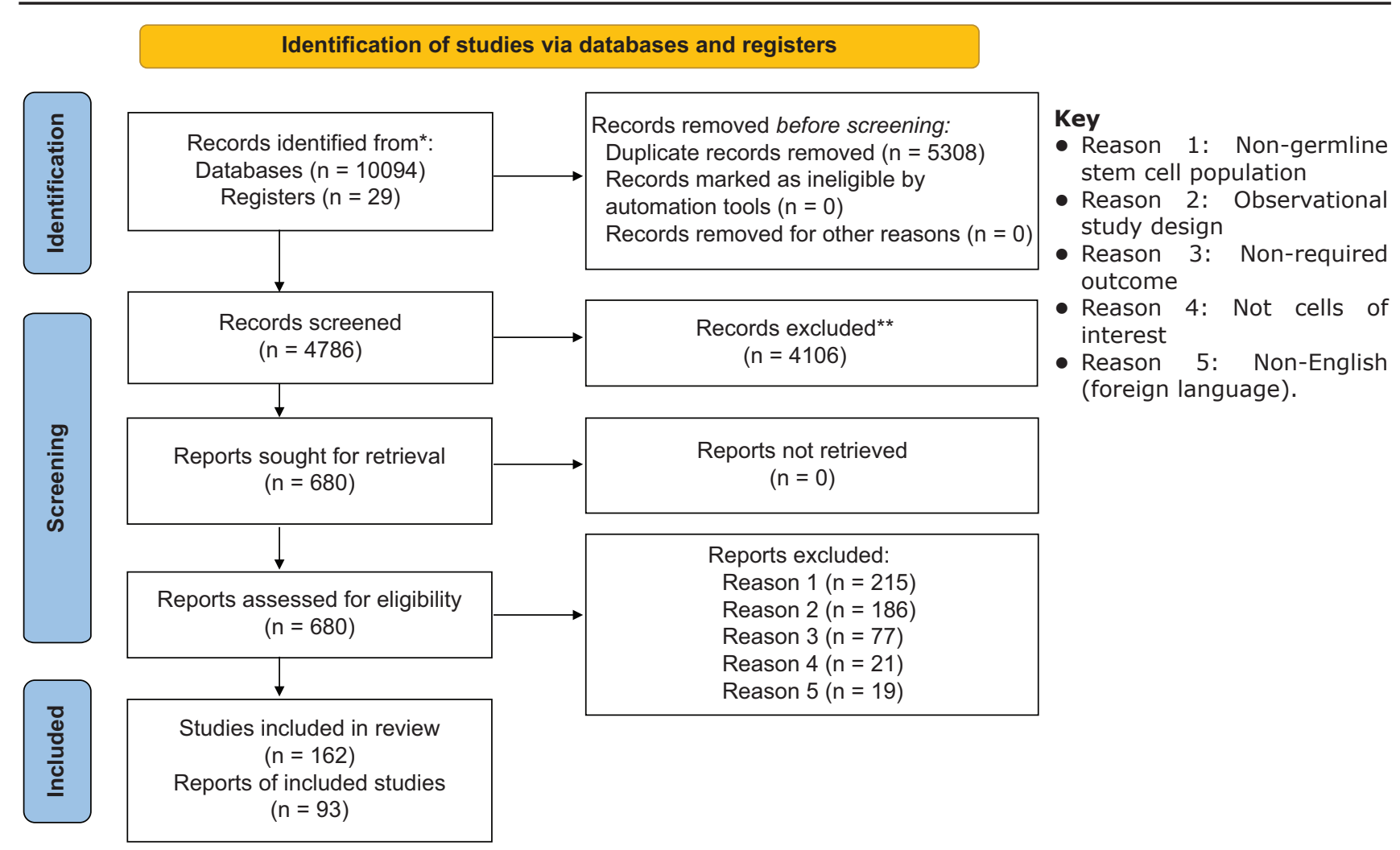

Figure-1: Preferred reporting items for systematic reviews and meta-analyses (PRISMA) literature search strategy [8].

long-term culture of the SSC for a period of $>21$ days (Table-1) [3-6,11,14-16]. From the review findings, the longest period of SSC culture was three months on a feeder cell monolayer (Sandos inbred mouse [SIM]-derived 6-thioguanine- and ouabain-resistant cells [STO]) using a serum-free medium (Knockout serum replacement) [6]. The SSC from immature and mature bovine testis stably expressed SSC markers during the culture period. Interestingly, SSC from mature testis required supplementation with drug 6-bromoindirubin-3'-oxime (BIO) in culture. The drug BIO activates the signaling pathway involved in the maintenance of undifferentiated spermatogonia from adult testes during the early stage of in vitro culture. In addition, bovine SSCs from an immature testis were maintained on serum-free medium on bovine fetal fibroblast feeder cells for 2 months [3]. However, when the bovine SSCs were cultured on laminin-coated plates (feeder-free) in preconditioned serum-free medium, the cells could only persist in culture for one month. These SSCs in culture expressed SSC-specific markers in cattle promyelocytic leukemia zinc finger $(P L Z F) / Z B T B 16$ and LIN28 [3]. Finally, bovine SSCs were also cultured in serum-free medium on bovine somatic testicular cells feeder layer for 3-12 weeks [5]. In general, from the findings of the review, long-term cultures of bovine SSC utilized serum-free medium on feeder cell layer with a cocktail of growth factors which included: Glial cell line-derived neurotrophic factor (GDNF), fibroblast growth factor 2 (FGF2), colony-stimulating factor-1, and stromal cell-derived factor (SDF-1). The long-term bovine SSC culture studies reported the detrimental effects of serum on SSC self-renewal and thus used a serumfree medium $[3,5,6]$. On the contrary, in sheep and goat, the long-term culture medium of SSC was supplemented with fetal bovine serum (FBS) [14,15]. The proliferation of SSC in culture was reported for extended periods although the evidence of SSC undifferentiated status through marker expression cells expressed CDH1, UCHL1, GFR 1, PLZF, and ITGA6 in sheep and of PLZF, $\alpha 6$ integrin in goats was not sufficient to conclude that the cultures were indeed made up of undifferentiated SSC.

\section{Characterization of SSC in culture using specific SSC markers in livestock}

Markers used for SSC characterization in the review included: VASA, PLZF, THYI (CD9), Ubiquitin carboxy-terminal hydrolase $1(U C H-L I)$ protein gene product 9.5 (PGP9.5), aIntegrins, Dolichosbiflorus agglutinin (DBA), OCT 4, GFR L1, LIN28, and NANOG (Table-2) [3-6,12,14,15,17-71]. In all studies $(\mathrm{n}=74)$, where SSCs were cultured, expression of more than one marker in SSC was evaluated for their identification, in addition to the typical morphology of germ cell colonies. UCH-L1, also called PGP9.5 was the most commonly used marker $(\mathrm{n}=47)$. Expression of PLZF transcription factor was evaluated in 21 studies and was also the main specific marker used for identification of bovine, caprine, and porcine SSC. Thymocyte differentiation antigen 1 (THY1) expression was reported in SSC in 15 studies. Evaluation of SSC expression of the LIN28 gene was conducted 
Table-1: Summary of studies with reports on the long-term culture of SSC in livestock species.

\begin{tabular}{|c|c|c|c|c|c|c|c|}
\hline $\begin{array}{l}\text { Culture } \\
\text { period }\end{array}$ & Species & $\begin{array}{l}\text { Age of } \\
\text { donor }\end{array}$ & $\begin{array}{l}\text { Culture } \\
\text { period }\end{array}$ & $\begin{array}{l}\text { Growth } \\
\text { factors }\end{array}$ & Medium used & $\begin{array}{l}\text { Markers } \\
\text { evaluation }\end{array}$ & $\begin{array}{l}\text { Culture } \\
\text { conditions }\end{array}$ \\
\hline $\begin{array}{l}\text { Suyatno } \\
\text { et al. [6] }\end{array}$ & Bovine & 3 months & 3 months & $\begin{array}{l}\text { LIF or } \\
\text { GDNF }\end{array}$ & $\begin{array}{l}15 \% \mathrm{KSR} \text { and } \\
1 \% \mathrm{FBS} \text { for } \\
5 \text { days } \mathrm{n} \text { then } \\
20 \% \mathrm{KSR}\end{array}$ & $\begin{array}{l}\text { Dome-shaped ES } \\
\text { cell-like colonies } \\
\text { UCHL-1, DBA. PCR } \\
\text { detection: NANOG, } \\
\text { OCT4, SOX2 }\end{array}$ & $\begin{array}{l}3 \text { months in SFM } \\
\text { in } 5 \% \mathrm{CO} 237^{\circ} \mathrm{C} \\
\text { STO feeder cells }\end{array}$ \\
\hline $\begin{array}{l}\text { Oatley } \\
\text { et al. [3] }\end{array}$ & Bovine & 4-5 months & 2 months & $\begin{array}{l}\text { GDNF, } \\
\text { FGF, LIF }\end{array}$ & $\begin{array}{l}\text { StemPro } \\
\text { serum-free }\end{array}$ & $\begin{array}{l}\text { Germ cell clumps } \\
\text { PLZF, LIN28, } \\
\text { GFRA1, ID4, } \\
\text { NANOS2 markers }\end{array}$ & $\begin{array}{l}5 \% \mathrm{CO}_{2}, 10 \% \mathrm{O}_{2} \\
\text { at } 35^{\circ} \mathrm{C} \text { on bovine } \\
\text { fetal fibroblast } \\
\text { feeder for } 2 \\
\text { months } \\
1 \text { month on } \\
\text { laminin-coated } \\
\text { plates } \mathrm{n} \\
\text { preconditioned } \\
\text { media }\end{array}$ \\
\hline Crouse, [5] & Bovine & 3-4 months & 3 weeks & $\begin{array}{l}\text { GDNF, } \\
\text { FGF, SCF } \\
\text { SDF }\end{array}$ & $\begin{array}{l}\text { StemPro } \\
\text { serum-free }\end{array}$ & $P L Z F$ & $\begin{array}{l}\text { 3-week BSC } \\
\text { feeder layer better } \\
\text { than BEF } 37^{\circ} \mathrm{C}\end{array}$ \\
\hline $\begin{array}{l}\text { Pramod } \\
\text { et al. [14] }\end{array}$ & Goat & 3-4 months & 2 months & NONE & $\begin{array}{l}10 \% \text { FBS on } \\
\text { Sertoli cell layer }\end{array}$ & $P L Z F, \alpha 6$ integrins & $\begin{array}{l}\text { Sertoli feeder layer } \\
37^{\circ} \mathrm{C}, 5 \% \mathrm{CO}_{2}\end{array}$ \\
\hline $\begin{array}{l}\text { Binsila } \\
\text { et al. [15] }\end{array}$ & Sheep & $\begin{array}{l}\text { Prepubertal } \\
\text { rams }\end{array}$ & 36 days & $\begin{array}{l}\text { GDNF, } \\
\text { IGF, EGF }\end{array}$ & $\begin{array}{l}\text { StemPro, } 10 \% \\
\text { FBS }\end{array}$ & $P L Z F$, ITGA, GFR $\alpha 1$ & $\begin{array}{l}\text { Laminin-coated } \\
\text { plates feeder-free } \\
\text { culture }\end{array}$ \\
\hline $\begin{array}{l}\text { Izadyar } \\
\text { et al. [16] }\end{array}$ & Bovine & 5 months & 3 months & none & $\begin{array}{l}2.5 \% \text { FCS in } \\
\text { MEM }\end{array}$ & $\begin{array}{l}D B A \text {, colonies, } \\
\text { cells differentiated } \\
\text { into spermatids }\end{array}$ & $\begin{array}{l}\text { Sertoli feeder layer } \\
5 \% \mathrm{CO} 2\end{array}$ \\
\hline $\begin{array}{l}\text { Dobrinski } \\
\text { et al. [11] }\end{array}$ & $\begin{array}{l}\text { Boar, } \\
\text { bovine }\end{array}$ & $\begin{array}{l}6 \text {-week boar, } \\
6 \text {-month } \\
\text { bovine }\end{array}$ & 1 month & none & DMEM & $\begin{array}{l}\text { None. Cells } \\
\text { transplanted to } \\
\text { mice testes }\end{array}$ & $\begin{array}{l}\text { STO feeder } 32^{\circ} \mathrm{C}, \\
5 \% \mathrm{CO}_{2}\end{array}$ \\
\hline $\begin{array}{l}\text { Aponte } \\
\text { et al. [4] }\end{array}$ & Bovine & 4-6 months & 25 days & None & $\begin{array}{l}\text { MEM with } \\
2.5 \% \text { FCS and } \\
\text { fungizone }\end{array}$ & $\begin{array}{l}\text { Blob-like colonies } \\
\text { Cells transplanted } \\
\text { to mice testes }\end{array}$ & $\begin{array}{l}\text { A monolayer } \\
\text { of Sertoli cell } \\
\text { developed in the } \\
\text { germ cell culture }\end{array}$ \\
\hline
\end{tabular}

$\mathrm{KSR}=$ Knockout serum replacement, SFM=Serum-free media, DMEM=Dulbecco's Modified Eagle Medium, MEM=Minimum essential media, FBS=Fetal bovine serum, FCS=Fetal calf serum, STO=Sandos inbred mouse (SIM)-derived 6-thioguanine- and ouabain-resistant (STO) cells, SDF=Stromal cell-derived factor, $\mathrm{SCF}=\mathrm{Stem}$ cell factor, $\mathrm{BEF}=\mathrm{Bovine}$ embryonic fibroblast

in only one study and was suggested to be uniquely expressed by SSC [3]. From the review, different studies used different markers for the verification of SSC undifferentiated status; however, expression of PLZF as being confined to SSC only not only rodents but also livestock has been supported by recent studies in bovine [3,5], sheep [17,18], pig [19], and goat [20,21].

\section{Transfection of SSC}

Transfection involves the methodologies of introducing foreign nucleic acids into host cells with integration in the cell genome. Transfection of SSC attempts was conducted in 11/93 studies (Table-3) [22 ,23,24,30,34,51,52,55,56,59,72]. The SSCs have been commonly transfected using viral vectors for gene delivery across the host cell membrane into the cell cytosol. Optimization of the SSC transfection methods and efficiency using the enhanced green fluorescent protein (eGFP) was done in 7/11 studies. The purpose for using the eGFP was to optimize the transfection protocols specifically for SSC and transmission of the gene was confirmed by the presence of green fluorescence in the donor cell population under a fluorescent microscope or flow cytometry. The eGFP-transfected cells were transplanted into the recipient testis and the animal was castrated after a period of time ranging from 1 week to 8 weeks. Colonization of donor cells or donor-derived spermatogenesis was evaluated through the detection of fluorescent donor cells in seminiferous tubules of recipients $[22,23,73]$. If donor SSCs are transplanted into compatible recipients, donor-derived spermatogenesis is expected if the donor cells successfully colonized the seminiferous tubules [74]. Detection of eGFP expressing spermatozoa and eGFP expressing embryos after in vitro fertilization using transgenic semen was successful $[24,75]$. The findings indicated that transduced SSCs were able to colonize the recipient testis, initiate donor-derived spermatogenesis, and produce transgenic sperm. However, quantification of the percentages of transgenic donor sperm/DNA was not reported.

Lipofectamine transfection was carried in $3 / 11$ studies. In the first study, the eGFP gene was transfected successfully into bovine SSC (transfection rate of 37\%) [30]. In the second study, the Enhancer of zeste homolog 2 gene was successfully knocked out in goat SSC using iRNAs against the gene [76]. In the third study, recombinant plasmid ( $p P L Z F-I R E S 2-$ $E G F P$ ) and lipofectamine reagent were effectively 
Table-2: Summary of markers used in SSC characterization in livestock species.

\begin{tabular}{|c|c|c|c|c|c|c|}
\hline Markers & Bovine & Ovine & Porcine & Caprine & Camel & Total \\
\hline$\overline{V A S A}$ & $\begin{array}{l}\text { Oatley et al. [3], } \\
\text { Kim et al. [22], } \\
\text { McMillan et al. [31] } \\
n=3\end{array}$ & $\begin{array}{l}\text { Borjigin et al. [32], } \\
\text { Borjigin et al. [17], } \\
\text { Herrid et al. [28] } \\
\mathrm{n}=4\end{array}$ & $\begin{array}{l}\text { Kim et al. [19], } \\
\text { Zhang et al. [33] } \\
n=2\end{array}$ & $\begin{array}{l}\text { Wu et al. [34], } \\
\text { Bahadorani et al. [29], } \\
\text { Wang et al. [35], } \\
\text { Niu et al. [36] } \\
\mathrm{n}=4\end{array}$ & 0 & $\mathrm{n}=12$ \\
\hline$P L Z F$ & $\begin{array}{l}\text { Oatley et al. [3], } \\
\text { Reding et al. [37], } \\
\text { Crouse et al. [5], } \\
\text { Cai et al. [38], } \\
\text { Anglin et al. [39], } \\
\text { McMillan et al. [31] } \\
n=6\end{array}$ & $\begin{array}{l}\text { Borjigin et al. [32], } \\
\text { Borjigin et al. [17] } \\
n=2\end{array}$ & $\begin{array}{l}\text { Lee et al. [40], } \\
\text { Lee et al. [41], } \\
\text { Lee et al. } \\
\text { Kim et al. [19], } \\
\text { Zhang et al. [33] } \\
\text { n=5 }\end{array}$ & $\begin{array}{l}\text { Abbasi et al. [42], } \\
\text { Pramod et al. [14], } \\
\text { Ren et al. [43], } \\
\text { Zhu et al. [44], } \\
\text { Bahadorani et al. [29], } \\
\text { Sharma et al. [21], } \\
\text { Abbasi et al. [23], } \\
\text { Song et al. [20] } \\
\mathrm{n}=8\end{array}$ & 0 & $n=21$ \\
\hline THY 1 & $\begin{array}{l}\text { Tajik et al. [30], } \\
\text { Giassetti et al. [45], } \\
\text { Reding et al. [37], } \\
\text { Nasiri et al. [46], } \\
\text { Youssefi et al. [47] } \\
n=5\end{array}$ & $\begin{array}{l}\text { Binsila et al. [18] } \\
n=1\end{array}$ & Not reported & $\begin{array}{l}\text { Abbasi et al. [42], } \\
\text { Wu et al. [34], } \\
\text { Ren et al. [43] } \\
\text { Bahadorani et al. [29], } \\
\text { Kaul et al. [26], } \\
\text { Sharma et al. [21], } \\
\text { Abbasi et al. [23], } \\
\text { Song et al. [20] } \\
\mathrm{n}=8\end{array}$ & 0 & $\mathrm{n}=14$ \\
\hline $\begin{array}{l}\text { UCHL1 } \\
\text { (PGP9.5) }\end{array}$ & $\begin{array}{l}\text { Suyatno et al. [6], } \\
\text { Giassetti et al. [48], } \\
\text { McMillan et al. [31]. } \\
\text { Kim et al. [49], } \\
\text { De Barros et al. [50], } \\
\text { Herrid et al. [27], } \\
\text { Kim et al. [22], } \\
\text { Herrid et al. [51], } \\
\text { Redden et al. [52] } \\
n=9\end{array}$ & $\begin{array}{l}\text { Binsila et al. [15], } \\
\text { Binsila et al. [18], } \\
\text { Pan et al. [53], } \\
\text { Moghaddam et al. } \\
\text { [54], } \\
\text { Zandi et al. [55], } \\
\text { Rodriguez-Sosa } \\
\text { et al. [56], } \\
\text { Borjigin et al. [17], } \\
\text { Herrid et al. [28] } \\
\mathrm{n}=8\end{array}$ & $\begin{array}{l}\text { Lin et al. [25], } \\
\text { Luo et al. [57], } \\
\text { Lee et al. [40], } \\
\text { Kim et al. [24], } \\
\text { Luo et al. [58], } \\
\text { Kim et al. [19] } \\
n=8\end{array}$ & $\begin{array}{l}\text { Sharma et al. [21] } \\
\text { Wang et al. [35] } \\
\text { Song et al. [20] } \\
\text { Zeng et al. [75] } \\
\text { Mohammad et al. [59] } \\
\text { Heidari et al. [60], } \\
\text { Shirazi et al. [61], } \\
\text { Heidari et al.[62] } \\
\mathrm{n}=8\end{array}$ & 0 & $n=33$ \\
\hline OCT 4 & $\begin{array}{l}\text { Tajik et al. [30], } \\
\text { Nasiri et al. 2012 [46], } \\
\text { Shafiei et al. [63], } \\
\text { Jabarpour and } \\
\text { Tajik,[64] } n=4\end{array}$ & $\begin{array}{l}\text { Qasemi-Panahi } \\
\text { et al.[65] } \\
\mathrm{n}=1\end{array}$ & Not reported & $\begin{array}{l}\text { Wang et al.[35] } \\
n=1\end{array}$ & 0 & $n=6$ \\
\hline$D B A$ & $\begin{array}{l}\text { Suyatno et al. [6], } \\
\text { Herrid et al. [66], } \\
\text { Izadyar et al. [12], } \\
\text { Aponte et al. [4], } \\
\text { Kim et al. [22], } \\
\text { Herrid et al. [51], } \\
\text { Redden et al. [52], } n=7\end{array}$ & Not reported & $\begin{array}{l}\text { Zhang et al.[33] } \\
\mathrm{n}=1\end{array}$ & $\begin{array}{l}\text { Bahadorani et al. [29], } \\
\text { Sharma et al. [21], } \\
\text { Song et al.[20] } \\
n=3\end{array}$ & 0 & $n=11$ \\
\hline Gfr1 & $\begin{array}{l}\text { Suyatno et al. [6], } \\
\text { Kim et al. [49], } \\
\text { De Barros et al. [50], } \\
\text { Oatley et al. } \\
n=4\end{array}$ & $\begin{array}{l}\text { Rasouli et al. [67], } \\
\text { Binsila et al.[15] } \\
n=2\end{array}$ & $\begin{array}{l}\text { Pan et al.[53] } \\
\mathrm{n}=1\end{array}$ & $\begin{array}{l}\text { Zhu et al.[44] } \\
\mathrm{n}=1\end{array}$ & 0 & $\mathrm{n}=8$ \\
\hline LIN28 & $\begin{array}{l}\text { Oatley et al.[3] } \\
\mathrm{n}=1\end{array}$ & Not reported & Not reported & Not reported & 0 & $\mathrm{n}=1$ \\
\hline NANOS2 & $\begin{array}{l}\text { Oatley et al.[3] } \\
\mathrm{n}=1\end{array}$ & Not reported & Not reported & Not reported & 0 & $\mathrm{n}=1$ \\
\hline$C D 9+$ & $\begin{array}{l}\text { Cai et al.[68] } \\
\mathrm{n}=1\end{array}$ & Not reported & Not reported & $\begin{array}{l}\text { Kaul et al.[69] } \\
\mathrm{n}=1\end{array}$ & 0 & $\mathrm{n}=2$ \\
\hline$C-K I T$ & $\begin{array}{l}\text { Dirami et al.[70] } \\
\mathrm{n}=0\end{array}$ & Not reported & Not reported & $\begin{array}{l}\text { Heidari et al. [60], } \\
\text { Heidari et al.[62], } \\
\text { Dirami et al. [10] } \\
\mathrm{n}=3\end{array}$ & 0 & $n=3$ \\
\hline CXCR4 & $\begin{array}{l}\text { Giassetti et al.[45] } \\
n=1\end{array}$ & Not reported & Not reported & Not reported & 0 & $\mathrm{n}=1$ \\
\hline Aintegrin & $\begin{array}{l}\text { Giassetti et al. [45], } \\
\text { De Barros et al. [50], } \\
\text { Giassetti et al. [48], } \\
\text { Kim et al.[22] } \\
n=4\end{array}$ & Not reported & Not reported & $\begin{array}{l}\text { Kumar et al.[14] } \\
n=1\end{array}$ & 0 & $n=5$ \\
\hline$C D 49 f$ & Not reported & Not reported & Not reported & $\begin{array}{l}\text { Wu et al. [71], Zhu } \\
\text { et al. }\end{array}$ & 0 & $n=2$ \\
\hline NANOG & $\begin{array}{l}\text { Lee et al. [40] } \\
\mathrm{n}=1\end{array}$ & Not reported & Not reported & Not reported & 0 & $\mathrm{n}=1$ \\
\hline
\end{tabular}


transfected into goat SSC to overexpress PLZF protein. Notably, the findings concluded the achievement of desired transfection effect through the use of liposomal carriers. The other method of transfection according to the review findings was nucleofection $(2 / 11)$. Nucleofection was successfully used to deliver transcription activator-like effector nucleases targeting Duchenne muscular dystrophy gene locus into porcine SSC nucleus [25]. Insertions and deletion mutations were detected in up to $18 \%$ of transfected cells. A similar technique was also used to deliver a transgene construct harboring the human growth hormone gene (hGH) and a chicken beta-globin insulator (CBGI) sequence in goat SSC [77]. These transfected SSCs were transplanted into recipient bucks. Genomic analysis of the recipient's semen revealed the presence of
hGH and CBGI sequences in $31.3 \pm 12.6 \%$ of ejaculates [77]. Finally, electroporation of SSC was reported in a single study, in which eGFP plasmid was introduced into porcine SSC. The cells were cultured and evaluated for green fluorescence, the transfection efficiency $>7.5 \%$, and $80 \%$ survival rates of cells (Table-3) [78].

\section{Recipient preparation methods in livestock species for germ cell transplantation}

Successful transplantation of SSC and production of semen of donor-derived genotype would enable utilization of this technology in natural livestock breeding systems and also gene-editing platforms (Table-4) [7,11,13,23,24,26-28,59,72, $73,75,77,79-87]$. From the review findings, SSC transplantation was conducted in four studies in bovine, four in goats, five in sheep, four in pigs, and

Table-3: Summary of reports on the methods of SSC transfection $(n=10)$.

\begin{tabular}{|c|c|c|c|c|c|}
\hline Author & Country & Species & $\begin{array}{l}\text { Transfection } \\
\text { method }\end{array}$ & Transgene & Transfection efficiency \\
\hline Tajik et al. [30] & Iran & Bovine & Lipofectamine & GFP & $37 \%$ uptake of transgene \\
\hline Kim et al. [24] & Korea & Pig & Lentivirus vector & GFP & $\begin{array}{l}\text { Detection of eGFP transgene in the } \\
\text { donor-derived transgenic sperm } \\
\text { and embryos after ICSI. 33\% (eGFP } \\
\text { expressing sperm was produced by } \\
\text { the two of six recipient pigs) of the } \\
\text { transplanted recipients produced } \\
\text { transduced sperm containing the genetic } \\
\text { modification }\end{array}$ \\
\hline Tang et al. [25] & Canada & Pig & nucleofection & $\begin{array}{l}\text { Duchenne } \\
\text { muscular } \\
\text { dystrophy gene } \\
\text { construct TALENs } \\
\text { DNA+eGFP }\end{array}$ & $\begin{array}{l}2.80-9 \% \text { indel mutations detected. Lower } \\
\text { survival of cells }\end{array}$ \\
\hline Kim et al. [22] & Korea & Bovine & Lentivirus vector & e-GFP & $\begin{array}{l}\text { The transduction efficiency was estimated } \\
\text { to be } 17 \% \text { of donor-derived genetically } \\
\text { modified cells which were present in the } \\
\text { testes of recipient mice } 2-3 \text { months after } \\
\text { xenotransplantation as evidenced by } \\
\text { expression of eGFP }\end{array}$ \\
\hline Abbasi et al. [23] & Iran & Goat & Lentivirus & eGFP & $\begin{array}{l}72 \% \text { of enriched cells were positive for } \\
\text { eGFP, transduced-enriched goat SSCs } \\
\text { could colonize within the cells into the } \\
\text { seminiferous tubules of germ cell-depleted } \\
\text { recipient mice }\end{array}$ \\
\hline $\begin{array}{l}\text { Rodriguez- } \\
\text { Sosa et al. [73] }\end{array}$ & Canada & Sheep & Lentivirus & eGFP & $\begin{array}{l}\text { Donor cells expressing eGFP detected in } \\
0.2 \% \text { ST of mice at } 2 \text { months }\end{array}$ \\
\hline Cai et al. [76] & China & Goat & Lipofectamine & $\begin{array}{l}\text { siRNAs targeting } \\
\text { EZH2 gene }\end{array}$ & EZH2 knockdown decrease cell viability \\
\hline Zeng et al. [75] & USA & Pig & AAV vector, LV & eGFP & $\begin{array}{l}\text { GFP in ( } 20 \% \text { and } 5.9 \% \text { of ejaculates. } \\
\text { The percentage of ejaculates that were } \\
\text { positive for the EGFP transgene ranged } \\
\text { from } 0 \% \text { to } 54.8 \% \text { for recipients of AAV } \\
\text { vector transduced germ cells (n } 1 / 417 \text { ) } \\
\text { and from } 0 \% \text { to } 25 \% \text { for recipients of LV } \\
\text { vector transduced germ cells }\end{array}$ \\
\hline Song et al. [20] & China & Goat & Lipofectamine & $\mathrm{p} P L Z F$-IRES2-EGFP & $\begin{array}{l}\text { Overexpression of } P L Z F \text { increased SCC } \\
\text { survival and renewal }\end{array}$ \\
\hline Zeng et al. [77] & & Goat & Nucleofection & $\begin{array}{l}\text { Transgene } \\
\text { constructs both } \\
\text { hGH and CBGI }\end{array}$ & $\begin{array}{l}\text { Genomic PCR for } \mathrm{hGH} \text { and CBGI } \\
\text { sequences; } 31.3 \pm 12.6 \% \text { of ejaculates } \\
\text { were positive for both } \mathrm{hGH} \text { and CBGI }\end{array}$ \\
\hline Kim et al. [96] & Korea & Pigs & Electroporation & eGFP & $\begin{array}{l}\text { Transfection efficiency }(>7.5 \%) \text { and } \\
\text { higher survival rates of cells }(>80 \%)\end{array}$ \\
\hline
\end{tabular}

$\mathrm{SSC}=$ Spermatogonial stem cells, GFP=Green fluorescent protein, eGFP=Enhanced green fluorescent protein, $\mathrm{EZH} 2=$ Enhancer of zeste homolog 2, PCR =Polymerase chain reaction, hGH=Human growth hormone, CBGI=Chicken beta-globin insulator 
Table-4: Studies reporting on transplantation of SSC and donor-derived spermatogenesis in livestock.

\begin{tabular}{|c|c|c|c|c|c|c|}
\hline Author & Country & Species & Testis cells & $\begin{array}{l}\text { Recipient } \\
\text { species }\end{array}$ & $\begin{array}{l}\text { Colonization of } \\
\text { transplanted cells }\end{array}$ & $\begin{array}{l}\text { Donor } \\
\text { spermatogenesis }\end{array}$ \\
\hline $\begin{array}{l}\text { Honaramooz } \\
\text { et al. [80] }\end{array}$ & USA & Goat & Fresh & $\begin{array}{l}\text { 3-5 months intact } \\
\text { germline goats }\end{array}$ & $\begin{array}{l}\text { Fluorescent cells } \\
\text { in the basement } \\
\text { membrane of ST } \\
\text { of recipients for } \\
12 \text { weeks }\end{array}$ & None \\
\hline $\begin{array}{l}\text { Herrid } \\
\text { et al. [72] }\end{array}$ & UAE & Camel & Fresh & $\begin{array}{l}D B A \text { germline } \\
\text { ablated camels }\end{array}$ & $\begin{array}{l}\text { Microsatellite } \\
\text { detection of donor } \\
\text { DNA in sperm }\end{array}$ & $\begin{array}{l}\text { Not able to quantify } \\
\text { the donor sperm } \\
\text { percentages in the } \\
\text { ejaculate }\end{array}$ \\
\hline $\begin{array}{l}\text { Shirazi } \\
\text { et al. [59] }\end{array}$ & Iran & Goat & $\begin{array}{l}\text { Cultured > } \\
3 \text { weeks }\end{array}$ & $\begin{array}{l}\text { Busulfan treated } \\
\text { mice }\end{array}$ & $\begin{array}{l}\text { Labelled cells in } \\
\text { mice seminiferous } \\
\text { tubules }\end{array}$ & None \\
\hline $\begin{array}{l}\text { Rodriguez } \\
\text {-Sosa } \\
\text { et al. [73] }\end{array}$ & Canada & Sheep & Fresh & $\begin{array}{l}\text { Germline intact } \\
\text { sheep }\end{array}$ & $\begin{array}{l}\text { eGFP donor cells } \\
\text { were in the average } \\
\text { of } 0.2 \% \text { of tubules } \\
\text { after } 2 \text { months }\end{array}$ & None \\
\hline $\begin{array}{l}\text { Mikkola } \\
\text { et al. [84] }\end{array}$ & Finland & Pig & Fresh & $\begin{array}{l}\text { Busulfan } \\
\text { treated (in } \\
\text { feed) pigs } \\
\text { with immotile } \\
\text { short-tail sperm } \\
\text { defect }\end{array}$ & $\begin{array}{l}\text { Donor-derived DNA } \\
\text { in semen }\end{array}$ & $\begin{array}{l}\text { Motile sperm in } \\
\text { recipients with } \\
\text { immotile short-tail } \\
\text { sperm defect }\end{array}$ \\
\hline $\begin{array}{l}\text { Herrid, } \\
\text { et al. [27] }\end{array}$ & Australia & Bovine & Fresh & $\begin{array}{l}\text { Intact germline } \\
\text { bulls }\end{array}$ & $\begin{array}{l}\text { Fluorescent labelled } \\
\text { cells in BM of ST } \\
\text { of recipients for } 6 \\
\text { months }\end{array}$ & Not reported \\
\hline $\begin{array}{l}\text { Izadyar } \\
\text { et al. [81] }\end{array}$ & Netherlands & Bovine & Fresh & Irradiated bovine & $\begin{array}{l}\text { Colonization } \\
\text { determined by } D B A \\
\text { staining }\end{array}$ & $\begin{array}{l}\text { (Confirmation } \\
\text { of donor sperm } \\
\text { reported) }\end{array}$ \\
\hline $\begin{array}{l}\text { Stockwell } \\
\text { et al. [82] }\end{array}$ & Australia & Bovine & Fresh & $\begin{array}{l}\text { Germline intact } \\
\text { bovine }\end{array}$ & $\begin{array}{l}\text { Presence of } \\
\text { fluorescent } \\
\text { cells in ST and } \\
\text { spermatogenesis }\end{array}$ & $\begin{array}{l}\text { Microsatellite } \\
\text { detection of for } \\
\text { presence of donor } \\
\text { DNA in the ejaculate }\end{array}$ \\
\hline $\begin{array}{l}\text { Honaramooz } \\
\text { et al. [79] }\end{array}$ & USA & Pig & Fresh & $\begin{array}{l}\text { Germline intact } \\
\text { pigs }\end{array}$ & $\begin{array}{l}\text { Fluorescent labelled } \\
\text { cells in BM of ST of } \\
\text { recipients }\end{array}$ & None \\
\hline $\begin{array}{l}\text { Kaul } \\
\text { et al. [26] }\end{array}$ & India & Goat & Fresh & $\begin{array}{l}\text { Germline intact } \\
\text { goats }\end{array}$ & $\begin{array}{l}\text { The fluorescent cells } \\
\text { were observed up } \\
\text { to } 12 \text { weeks after } \\
\text { transplantation }\end{array}$ & None \\
\hline $\begin{array}{l}\text { Honaramooz } \\
\text { et al. [80] }\end{array}$ & USA & Goat & Fresh & $\begin{array}{l}\text { Germline intact } \\
\text { goats }\end{array}$ & $\begin{array}{l}\text { Donor-derived } \\
\text { spermatogenesis }\end{array}$ & $\begin{array}{l}\text { Sperm carrying } \\
\text { the donor-derived } \\
\text { transgene human } \\
\text { alpha-1 antitrypsin } \\
\text { expression } \\
\text { construct detected } \\
\text { in the ejaculates }\end{array}$ \\
\hline $\begin{array}{l}\text { Joerg } \\
\text { et al. [85] }\end{array}$ & Switzerland & Bovine & Fresh & $\begin{array}{l}\text { Non-mosaic } \\
\text { Klinefelter bovine }\end{array}$ & $\begin{array}{l}\text { The donor cells } \\
\text { were rejected }\end{array}$ & None \\
\hline $\begin{array}{l}\text { Oatley } \\
\text { et al. [13] }\end{array}$ & USA & Bovine & $\begin{array}{l}\text { Fresh, } \\
\text { Cultured cells }\end{array}$ & $\begin{array}{l}\text { Busulfan-treated } \\
\text { mice }\end{array}$ & $\begin{array}{l}\text { Fresh cells colonized } \\
\text { ST. Cultured cells } \\
\text { did not }\end{array}$ & None \\
\hline $\begin{array}{l}\text { Dobrinski } \\
\text { et al. [11] }\end{array}$ & USA & Bovine & $\begin{array}{l}\text { Cultured > } \\
3 \text { weeks }\end{array}$ & Busulfan mice & $\begin{array}{l}\text { Colonization of } \\
\text { ST basement } \\
\text { membrane }\end{array}$ & None \\
\hline $\begin{array}{l}\text { Herrid } \\
\text { et al. [28] }\end{array}$ & Australia & Sheep & Fresh & Irradiated sheep & $\begin{array}{l}\text { Donor DNA detected } \\
\text { in the ejaculate }\end{array}$ & $\begin{array}{l}\text { Microsatellite } \\
\text { detection of donor } \\
\text { DNA in ejaculate }\end{array}$ \\
\hline $\begin{array}{l}\text { Herrid } \\
\text { et al. [86] }\end{array}$ & Australia & Sheep & Fresh & Irradiated sheep & $\begin{array}{l}\text { Donor DNA detected } \\
\text { in the ejaculate }\end{array}$ & $\begin{array}{l}\text { Microsatellite } \\
\text { detection of donor } \\
\text { DNA in ejaculate }\end{array}$ \\
\hline $\begin{array}{l}\text { Kim } \\
\text { et al. [24] }\end{array}$ & Korea & Pig & $\begin{array}{l}\text { Fresh } \\
\text { (pLV-TH-GFP) } \\
\text { cells }\end{array}$ & $\begin{array}{l}\text { In utero busulfan } \\
\text { treated pig }\end{array}$ & $\begin{array}{l}\text { Colonies of } \\
\text { transduced SSC } \\
\text { in the recipients' } \\
\text { testes. }\end{array}$ & $\begin{array}{l}\text { eGFP expressing } \\
\text { ejaculates used for } \\
\text { ICSI/IVF to produce } \\
\text { GFP expressing } \\
\text { embryos }\end{array}$ \\
\hline $\begin{array}{l}\text { Ciccarelli } \\
\text { et al. [7] }\end{array}$ & USA & $\begin{array}{l}\text { Boar, } \\
\text { Goat, } \\
\text { Bull }\end{array}$ & Fresh & NANOS2 knocks & $\begin{array}{l}\text { Donor-derived } \\
\text { spermatogenesis }\end{array}$ & $\begin{array}{l}\text { Sperm } 100 \% \\
\text { donor-derived } \\
\text { genotype }\end{array}$ \\
\hline
\end{tabular}


Table-4: (Continued).

\begin{tabular}{|c|c|c|c|c|c|c|}
\hline Author & Country & Species & Testis cells & $\begin{array}{l}\text { Recipient } \\
\text { species }\end{array}$ & $\begin{array}{l}\text { Colonization of } \\
\text { transplanted cells }\end{array}$ & $\begin{array}{l}\text { Donor } \\
\text { spermatogenesis }\end{array}$ \\
\hline $\begin{array}{l}\text { Zeng } \\
\text { et al. [75] }\end{array}$ & USA & Pigs & $\begin{array}{l}(\mathrm{AAV}),(\mathrm{LV}) \\
\text { transduced } \\
\text { SSC }\end{array}$ & $\begin{array}{l}\text { Busulfan-treated } \\
\text { pigs }\end{array}$ & $\begin{array}{l}\text { eGFP transgene } \\
\text { ranged from } 0 \% \text { to } \\
54.8 \% \text { for recipients } \\
\text { of AAV. About } \\
0-25 \% \text { for recipients } \\
\text { of LV transfected } \\
\text { germ cells }\end{array}$ & $\begin{array}{l}\text { Semen from AAV } \\
\text { recipients was } \\
\text { used for (IVF), } \\
9.09 \% \text { and } 64.3 \% \\
\text { of embryos were } \\
\text { transgenic }\end{array}$ \\
\hline $\begin{array}{l}\text { Rodriguez } \\
\text {-Sosa } \\
\text { et al. [73] }\end{array}$ & Canada & Sheep & Fresh & $\begin{array}{l}\text { Non-treated } \\
\text { sheep }\end{array}$ & $\begin{array}{l}\text { Donor cells } \\
\text { expressing eGFP } \\
\text { detected in ST at } 2 \\
\text { months }\end{array}$ & None \\
\hline $\begin{array}{l}\text { Abbasi } \\
\text { et al. [23] }\end{array}$ & Iran & Goat & $\begin{array}{l}\text { Fresh LV-EGFP } \\
\text { transduced } \\
\text { cells }\end{array}$ & $\begin{array}{l}\text { Busulfan-treated } \\
\text { mice }\end{array}$ & $\begin{array}{l}\text { Transduced goat } \\
\text { SSCs colonized } \\
\text { mice seminiferous } \\
\text { tubules }\end{array}$ & None \\
\hline $\begin{array}{l}\text { Oatley } \\
\text { et al. [87] }\end{array}$ & USA & Bovine & $\begin{array}{l}2 \text { weeks } \\
\text { culture in } \\
\text { testes explant }\end{array}$ & $\begin{array}{l}\text { Busulfan-treated } \\
\text { mice }\end{array}$ & $\begin{array}{l}\text { Colonies of SSC in } \\
\text { the seminiferous } \\
\text { tubules of mice }\end{array}$ & None \\
\hline $\begin{array}{l}\text { Zeng } \\
\text { et al. [77] }\end{array}$ & USA & Goat & $\begin{array}{l}\text { Fresh } \\
\text { transduced } \\
\text { (human } \\
\text { growth } \\
\text { hormone-GH) } \\
\text { SSC }\end{array}$ & Irradiation & $\begin{array}{l}\text { Of } 62 \text { ejaculates, } \\
63.9 \pm 17.3 \% \text { were } \\
\text { positive for hGH and } \\
42.5 \pm 12.0 \% \text { were } \\
\text { positive for CBGI }\end{array}$ & $\begin{array}{l}\text { Donor-derived } \\
\text { spermatogenesis }\end{array}$ \\
\hline $\begin{array}{l}\text { Stockwell } \\
\text { et al. [83] }\end{array}$ & Australia & Ram & Fresh & Irradiated ram & $\begin{array}{l}\text { Donor DNA detected } \\
\text { in the ejaculate }\end{array}$ & $\begin{array}{l}\text { Low levels of donor } \\
\text { DNA }\end{array}$ \\
\hline
\end{tabular}

$\mathrm{SSC}=$ Spermatogonial stem cells, GFP=Green fluorescent protein, eGFP=Enhanced green fluorescent protein, hGH=Human growth hormone, CBGI=Chicken beta-globin insulator, GH=Growth hormone, ICSI/IVF=Intracytoplasmic sperm injection/In vitro fertilization, AAV=Adeno-associated virus, IVF, LV=Lentiviral vectors, ST=Seminiferous tubules, $\mathrm{BM}=$ Bone marrow

one in camel. Transplantation of testicular cells into livestock recipients began in 2002 [79-81], although earlier reports had documented transplantation of livestock species SSC into mice recipient testes $[11,13]$.

The success of transplantation with resultant donor-derived spermatogenesis can only be achieved through endogenous depletion of the germ cell layer of the recipient animal. In the current review, ablation of the germline layer through irradiation was conducted in five studies, ablation through the use of chemotoxic drug busulfan carried out in three studies; use of $D B A$ in one study, and NANOS2 gene knockout ( $\mathrm{n}=1)$ (Table-4). Busulfan germline ablated mice recipients were used in five studies for evaluation colonization of labeled SSC into the seminiferous tubules. When transplantation was done using mice recipients or germline intact livestock recipients, the donor SSCs were labeled with fluorescent markers such as Red linker dye [26] or transfected with eGFP before transplantation. The fluorescence enables the identification of donor cells or spermatozoa through fluorescent microscopy or flow cytometry. Transplantation of SSC into germline intact was conducted in earlier studies in boars, bucks, and sheep $[26,27,73,74,79,82]$.

Exposing the testes to prescribed doses of irradiations destroys the germline layer. This method was used in several studies to prepare recipients and reported the presence of donor DNA or donor transgenes in the semen of recipients following transplantation of donor SSC [28,77,81-83]. Use of irradiated recipients was an effective method of recipient preparation although the challenges included; (i) use of high levels of irradiation would cause bone marrow depression and systemic toxicity, (ii) there was a decline in donor spermatozoa in semen ejaculates of recipients over a period and quantification of donor DNA was a problem due to low percentage in semen [82].

Treatment with the busulfan drug temporarily ablates the germline layer giving a narrow window for regeneration of donor-derived spermatogenesis after transplantation of SSC. In the three studies that prepared recipients using busulfan treatment, there were reports of derived spermatogenesis through the detection of donor DNA in semen [84] or eGFP expressing spermatozoa that were used for in vitro fertilization to produce eGFP expressing embryos [24,75]. Although quantification of the levels of donor DNA in the semen from the recipients was not carried out and the low levels of donor DNA were indicative of a low percentage of donor-derived spermatogenesis due to the presence of endogenous spermatogenesis. Germline ablation through treatment with $D B A$ was conducted in camels in one study. Donor-derived DNA was detected in the ejaculates of $D B A$ treated recipients following transplantation of the testis cells [72]. To overcome the challenges associated with temporary ablation of germline layer, recently 
genetically germline deficient recipients were generated [7]. The recipients were generated through knockout of NANOS2 gene, which is responsible for germline development. Hence, the germline layer fails to develop, but somatic cell support is fully developed and functional $[7,88]$. Transplantation of SSC into the NANOS2 knockout boar, bucks, and bull recipients resulted in the regeneration of complete and continuous donor-derived spermatogenesis [7] (Table-4).

\section{Discussion}

This study compiled the literature published on in vitro culture systems and applications in livestock production from January 1990 to February 2021. The main focus of the review was to have an overview of the current developments in SSC culture techniques, methods of recipient preparation, and intra-testicular transplantation methodologies in livestock. The emergence of precise gene-editing technologies such as clustered regularly interspaced short palindromic repeats (CRISPR) provides an opportunity for harnessing SSC potential as a transgene carrier, for in vitro gene manipulation and development of transgenic animals. With the low number of SSC in the total testicular cell population, long-term in vitro culture of the cells is required to amplify to millions the few numbers of SSC freshly isolated, which would be adequate for gene editing and transplantation [1].

From the current review, the methodology for long-term culture is still not fully standardized and commonly carried out as it was reported only in seven studies. The long-term culture of SSCs involved either of the two strategies: First, by supplementation of culture medium with a cocktail of growth factors (GDNF, bFGF, LIF, stem cell factor, and SDF); second, by growing SSCs on a feeder cell layer or feeder cellsfree culture using preconditioned serum-free media. Early studies utilized serum as one of the important components of culture medium, although published reports have shown that the presence of serum in the medium enhances the growth of somatic cells and inhibits SSC self-renewal [3,5,6,21]. Culture studies of goat SSC in media containing 10\% FBS have been documented $[14,15]$. However, the cultured cells did not exhibit a typical morphology of germ cell clumps as described by Oatley et al. [3], Bahadorani et al. [89]. Additionally, transplantation of the cultured SSC which is a definitive test to verify the stem cell capacity of cultured SSC was not carried out. Recent studies for goat SSC have demonstrated the detrimental effects of serum on SSC self-renewal and the enhanced proliferation of somatic cells in SSC culture medium containing serum $[21,29]$. The long-term culture of SSC has failed mainly due to difficulties in providing all in vitro conditions that mimic the in vivo SSC niche, which has physical, mechanical, and chemical support by the surrounding somatic cells and lack of unique markers for SSC identification in culture [90]. There has been a controversy on the unique markers used to identify SSCs due to their non-specificity to SSC cell type, with some of the markers being expressed by other germ cell subtypes and even somatic cells. Expression of commonly SSC markers used in most studies: UCHL1, OCT4, SOX2, KLF4, and THY1) is not restricted to undifferentiated spermatogonia only $[3,91]$. At present, the only unequivocal measure of SSC existence within a culture dish is through transplantation into a germline ablated recipient testis to assess the capacity for the reestablishment of spermatogenesis. From the findings of this, none of the long-term culture studies conducted transplanted the cultured SSC to a recipient testis for the assessment of donor-derived spermatogenesis, hence the absence of enough evidence for long-term maintenance of SSC in their undifferentiated status. Most studies on successful long-term culture and maintenance of SSC in culture were based on findings from presumptive marker expression: PLZF, LIN28, NANOS2, and GFR 1 1 with high similarity of the cell clump morphology to bonafide mouse cultures of SSC $[3,5,92,93]$.

Notwithstanding, morphological characteristics of SSC germ cell clumps consisting of a cluster of cells resembling a bunch of grapes with clear cell borders have been documented, and similarity in morphology with livestock, SSCs have been reported [3,6,70,94]. This characteristic germ cell clump of SSC in culture is an indication of the existence of undifferentiated spermatogonia stem cells (not definitive measure) [94]. Regarding culture conditions, the use of feeder cells for SSC cultures is still taking the lead as compared to feeder-free culture. Cultures of SSC of STO feeders performed better than Sertoli cell feeders or other somatic cells (fibroblast) feeder cells. The growth of SSC on feeders presents a major challenge in transplantation of SSC as they may interfere with colonization in the recipient testes [3]; therefore, there has to be a way to culture these cells feeder free. Preconditioned media on feeder cells and culture of cells in laminin-coated plates have shown promise of success in the long-term maintenance of the SSC in culture $[3,15]$. Although the morphological characteristics and marker identification are promising findings toward standard conditions for long-term cultures of SSC in livestock species, the stem cell activity of the spermatogonial populations must be assessed by intratesticular transplantation to recipient livestock species.

Transplantation of SSC and regeneration of donor-derived spermatogenesis is the definitive proof and potential for using the SSC cultures in livestock production. Several hurdles have been experienced in translating the germ cell transplantation procedures to livestock species from rodents, where it has successfully been achieved. The difficulty has been attributed to the low number of SSC within the heterogeneous germ cell population and lack of methods to prepare germline ablated males with functional testicular somatic cell ultrastructure. Ablation of the 
endogenous germ cell layer avails empty niches for colonization by exogenous SSC, thus regeneration for donor-derived spermatogenesis. Methodology of intratesticular transplantation of the SSC through ultrasound-guided rete testis injection technique is well standardized. However, the success and sustainability of donor-derived spermatogenesis require a male that is permanently/genetically germline ablated but with functional somatic cell structures as in the case with the gene-edited NANOS2 gene knockouts published by Ciccarelli et al. [7].

Chemical and physical methods to induce germ cell apoptosis have been used to prepare recipients. However, there is a gradual regeneration of endogenous recipient spermatogenesis, with the endogenous SSC occupying the stem cell niches, thus preventing effective colonization of the basement membrane by transplanted donor SSC. Hence, donor-derived spermatogenesis in such recipients becomes challenging to quantify.

Transplantation of livestock species SSC into mice recipients does not result in donor-derived spermatogenesis due to different genetic signaling mechanisms. However, the livestock SSCs can colonize the mice seminiferous tubules, as evidenced by immunohistochemistry experiments. Donor-derived spermatogenesis necessitates transplantation into the same species of animals as documented in pigs by Zeng et al. [75], Kim et al. [24].

The chemotoxic drug busulfan has detrimental effects on other fast-dividing cells such as bone marrow cells, which results in untargeted systemic damage affecting various organs in the recipient animals. In addition, the somatic cell population is also destroyed, thus affecting the robustness of spermatogenesis [91]. Regardless of the route of busulfan administration to recipient animals, whether done in feed or systemic administration, in all studies that used this drug, the recipients showed a resumption of endogenous spermatogenesis with the production of semen having the recipient's genotype. However, donor-derived spermatogenesis also occurred with low levels of donor DNA irregularly detected by microsatellite markers, but the levels declined with time [24,75,84].

In addition, the use of irradiation to deplete endogenous germ cells is also cytotoxic to the somatic cell population, testicular seminiferous tubular structure, and the rest of the cells in the body, which may limit the capacity for donor SSC colonization. Testicular irradiation causes temporary depletion of endogenous germ cells [95]. $D B A$, which is a plant-based lectin with selective toxicity to bovine Type A spermatogonia also resulted in temporary germline ablation with the detection of donor DNA in recipients ejaculate, although the authors were not able to quantify the amount of donor-derived sperm in the ejaculate [72].

Notably, efforts have been made in using recipients with temporary germline ablation for transplantation with donor SSC. However, in most cases, the presence of both donor-derived and recipient endogenous spermatogenesis makes it challenging to quantify the intended donor-derived spermatogenesis conclusively. In general, methods that result in temporary germline ablation are ineffective, especially if the intended end result is to use the technology as an alternative breeding technology in livestock production systems. To utilize the potential of germ cell technology in livestock species, several researchers have suggested genetic engineering of surrogates/recipients that are genetically germline ablated but have intact testicular tubular structure and functional somatic cell support [88]. This will avail SSC niches that will be occupied by exogenous donor SSC to enable colonization basement membrane by these cells after transplantation. This would lead to $100 \%$ donor-derived spermatogenesis. From the findings in the review, SSC transplantation recipients were successfully generated through gene editing to knockout NANOS2 gene. Complete donor-derived spermatogenesis was confirmed in the recipients [7].

Precise gene editing technologies are growing faster, and SSC is the new frontier for gene manipulation and dissemination of desirable elite genetics. The SSC populations are progenitor cells for spermatozoa, and hence, it would be easier to spread the gene of interest if gene-edited SSCs are used in transplantation. In vitro gene manipulation of SSC and subsequent transplantation will be helpful in the development of transgenic livestock. Successful attempts to generate transgenic animals by using SSC have been made in rodents [96]. So far, none of the studies in which SSC transfection was carried out aimed at the introduction of genes targeting disease resistance or production traits of interest, hence this research area remains unexploited. The main focus of the studies was to determine the potential transfection efficiency of different methods using the eGFP reporter gene or other transgenes in a few cases, of which transfection success was varied in all of the studies, with most of them below $10 \%$. Although the findings are intriguing, there is still more research to be conducted in this area as the most efficient method of viral transduction of SSC using viral vectors has associated safety risks, especially if the cells are going to be transplanted into live recipients [77]. Other methods for introduction of exogenous genes into cells such as nucleofection [25] and lipofectamine transfection [30,76] have been shown to have great potential for exploitation of in vitro gene manipulation of SSC. Finally, prepubertal animals have been poised as the best donors for SSC since, at this age, most gonocytes have differentiated to spermatogonia, thus maximum harvesting of mitotically active SSC. At this age, the seminiferous tubules are only made up of Sertoli cells and undifferentiated spermatogonia/SSC [97]. Therefore, the population of germ cells isolated is likely to contain a high population of SSC. 


\section{Conclusion}

Great strides have been made on male germline stem cells culture and utilization of SSC cells in livestock production since the year 2000, when active SSC studies in livestock species were initiated. So far, the conditions for long-term culture of SSCs which include using a serum-free medium with a cocktail of growth factors with or without feeder cells have been optimized but there is still a need for more research to develop standardized methodology across the livestock species. Following the generation of ideal surrogate sires, transfer of SSC from donor male to recipients will allow the dissemination of superior gametes through breeding. However, more research on the performance of gene-edited surrogates in field conditions should be conducted, as well as assess natural mating and fertility capacity.

The successful performance of surrogate sires transplanted with donor SSC would enable effective utilization of this technology especially in arid and semi-arid regions of sub-Saharan Africa where the uptake of more commonly applied breeding technologies has largely been hindered by culture and lack of functional infrastructure. Despite a high proportion of livestock in sub-Saharan Africa being in the arid and semi-arid areas, research on this reproductive technology has not been carried out. Hence, the importance of developing the surrogate sire technology using livestock that is already adapted to these harsh environments for the benefit of inhabitant communities. The International Livestock Research Institute in Kenya, Africa, has embarked on a study to culture goat SSCs and transfer of the NANOS2 gene-editing technology to develop surrogate sires of indigenous goats. The success of this project in Africa will be a great milestone in the utilization of this new breeding technology in sub-Saharan Africa.

\section{Authors' Contributions}

WN: Contributed to data collection, data interpretation, and manuscript drafting. ANK: Contributed to data collection and manuscript review. JNM: Manuscript revision and Ph.D. supervisor. CT: Critical manuscript revision. SK: Project conceptual design, principal scientist of the project, and Ph.D. supervisor. All authors reviewed and approved the final manuscript.

\section{Acknowledgments}

This study was funded by CGIAR Research Program on Livestock, Nairobi, Kenya (https://livestock.cgiar.org/) and the Centre for Tropical Livestock Genetics and Health, Nairobi, Kenya (Grant number: OPP01127286).

\section{Competing Interests}

The authors declare that they have no competing interests.

\section{Publisher's Note}

Veterinary World remains neutral with regard to jurisdictional claims in published institutional affiliation.

\section{References}

1. Oatley, J.M. and Brinster, R.L. (2012) The germline stem cell niche unit in mammalian testes. Physiol. Rev., 92(2): 577-595.

2. de Rooij, D.G. (2015) The spermatogonial stem cell niche in mammals. In: Sertoli Cell Biology Second E, editor. Griswold MDBT-SCB. Academic Press, Oxford. p99-121.

3. Oatley, M.J., Kaucher, A.V., Yang, Q.E., Waqas, M.S. and Oatley, J.M. (2016) Conditions for long-term culture of cattle undifferentiated spermatogonia. Biol. Reprod., 95(1): 14.

4. Aponte, P.M., Soda, T., van de Kant, H.J.G. and de Rooij, D.G. (2006) Basic features of bovine spermatogonial culture and effects of glial cell line-derived neurotrophic factor. Theriogenology, 65(9): 1828-1847.

5. Crouse, R.A., Oatley, M.J. and Oatley, J.M. (2012) Identification of conditions supporting in vitro maintenance of bovine undifferentiated spermatogonia. Biol. Reprod., 85(Suppl 1): 769.

6. Suyatno, Kitamura, Y., Ikeda, S., Minami, N., Yamada, M. and Imai, H. (2018) Long-term culture of undifferentiated spermatogonia isolated from immature and adult bovine testes. Mol. Reprod. Dev., 85(3): 236-249.

7. Ciccarelli, M., Giassetti, M.I., Miao, D., Oatley, M.J., Robbins, C., Lopez-Biladeau, B., Waqas, M.S., Tibary, A., Whitelaw, B., Lillico, S., Park, C.H., Park, K.E., Telugu, B., Fan, Z., Liu, Y., Regouski, M., Polejaeva, I.A. and Oatley, J.M. (2020) Donor-derived spermatogenesis following stem cell transplantation in sterile NANOS2 knockout males. Proc. Natl. Acad. Sci. U. S. A., 117(39): 24195-24204.

8. Page, M.J., McKenzie, J.E., Bossuyt, P.M., Boutron, I., Hoffmann, T.C., Mulrow, C.D., Shamseer L, Tetzlaff, J.M., Akl, E.A., Brennan, S.E., Chou, R., Glanville, J., Grimshaw, J.M., Hróbjartsson, A., Lalu, M.M., Li, T., Loder, E.W., Mayo-Wilson, E., McDonald, S., McGuinness, L.A., Stewart, L.A., Thomas, J., Tricco, A.C., Welch, V.A., Whiting, P. and Moher, D. (2021) The PRISMA 2020 statement: An updated guideline for reporting systematic reviews. $B M J, 372$

9. Ouzzani, M., Hammady H., Fedorowicz, Z. and Elmagarmid, A. (2016) Rayyan a web and mobile app for systematic reviews. Syst. Rev., 5(1): 210

10. Dirami, G., Ravindranath, N., Pursel, V. and Dym, M. (1999) Effects of stem cell factor and granulocyte macrophage-colony stimulating factor on survival of porcine Type A spermatogonia cultured in KSOM. Biol. Reprod., 61(1): 225-230.

11. Dobrinski, I., Avarbock, M.R. and Brinster, R.L. (2000) Germ cell transplantation from large domestic animals into mouse testes. Mol. Reprod. Dev., 57(3): 270-279.

12. Izadyar, F., Spierenberg, G.T., Creemers, L.B., den Ouden, K. and de Rooij, D.G. (2002) Isolation and purification of Type A spermatogonia from the bovine testis. Reproduction, 124(1): 85-94.

13. Oatley, J.M., De Avila, D.M., McLean, D.J., Griswold, M.D. and Reeves, J.J. (2002) Transplantation of bovine germinal cells into mouse testes. J. Anim. Sci., 80(7): 1925-1931.

14. Pramod, R.K. and Mitra, A. (2014) In vitro culture and characterization of spermatogonial stem cells on Sertoli cell feeder layer in goat (Capra hircus). J. Assist. Reprod. Genet., 31(8): 993-1001.

15. Binsila, B.K., Selvaraju, S., Ghosh, S.K., Ramya, L., Arangasamy, A. and Ranjithkumaran, R. (2020) EGF, GDNF, and IGF-1 influence the proliferation and stemness of ovine spermatogonial stem cells in vitro. J. Assist. Reprod. Genet., 37(10): 2615-2630. 
16. Izadyar, F., Den Ouden, K., Creemers, L.B., Posthuma, G., Parvinen, M. and De Rooij, D.G. (2003) Proliferation and differentiation of bovine Type A spermatogonia during long-term culture. Biol. Reprod., 68(1): 272-281.

17. Borjigin, U., Davey, R., Hutton, K. and Herrid, M. (2010) Expression of promyelocytic leukaemia zinc-finger in ovine testis and its application in evaluating the enrichment efficiency of differential plating. Reprod. Fertil. Dev., 22(5):733-742.

18. Binsila, K.B., Selvaraju, S., Ghosh, S.K., Parthipan, S., Archana, S.S., Arangasamy, A., Prasad, J.K., Bhatta, R. and Ravindra, J.P. (2018) Isolation and enrichment of putative spermatogonial stem cells from ram (Ovis aries) testis. Anim. Reprod. Sci., 196: 9-18.

19. Kim, Y.H., Kim, B.J., Kim, B.G., Lee, Y.A., Kim, K.J., Chung, H.J., Hwang, S., Woo, J.S., Park, J.K., Schmidt, J.A., Pang, M.G. and Ryu, B.Y. (2013) Stage-specific embryonic antigen-1 expression by undifferentiated spermatogonia in the prepubertal boar testis. J. Anim. Sci., 91(7): 3143-3154.

20. Song, W., Zhu, H., Li, M., Li, N., Wu, J., Mu, H., Yao, X., Han, W., Liu, W. and Hua, J. (2013) Promyelocytic leukaemia zinc finger maintains self-renewal of male germline stem cells (mGSCs) and its expression pattern in dairy goat testis. Cell Prolif., 46(4): 457-468.

21. Sharma, A., Shah, S.M., Tiwari, M., Roshan, M., Singh, M.K., Singla, S.K., Palta, P., Manik, R.S. and Chauhan, M.S. (2020) Propagation of goat putative spermatogonial stem cells under growth factors defined serumfree culture conditions. Cytotechnology, 72(3): 489-497.

22. Kim, K.J., Cho, C.M., Kim, B.G., Lee, Y.A., Kim, B.J., Kim, Y.H., Kim, C.G., Schmidt, J.A. and Ryu, B.Y. (2014) Lentiviral modification of enriched populations of bovine male gonocytes. J. Anim. Sci., 92(1): 106-118.

23. Abbasi, H., Hosseini, S.M., Hajian, M., Nasiri, Z., Bahadorani, M., Tahmoorespur, M., Nasiri, M.R. and NasrEsfahani, M.H. (2015) Lentiviral vector-mediated transduction of goat undifferentiated spermatogonia. Anim. Reprod. Sci., 163: 10-17.

24. Kim, B.G., Kim, Y.H., Lee, Y.A., Kim, B.J., Kim, K.J., Jung, S.E., Chung, H.J., Hwang, S., Choi, S.H., Kim, M.J., Kim, D.H., Kim, I.C., Kim, M.K., Kim, N.H., Kim, C.G. and Ryu, B.Y. (2014) Production of transgenic spermatozoa by lentiviral transduction and transplantation of porcine spermatogonial stem cells. Tissue Eng. Regen. Med., 11(6): 458-466.

25. Tang, L., Bondareva, A., González, R., RodriguezSosa, J.R., Carlson, D.F., Webster, D., Fahrenkrug, S. and Dobrinski, I. (2018) TALEN-mediated gene targeting in porcine spermatogonia. Mol. Reprod. Dev., 85(3): 250-261.

26. Kaul, G., Kaur, J. and Rafeeqi, T.A. (2010) Ultrasoundguided transplantation of enriched and cryopreserved spermatogonial cell suspension in goats. Reprod. Domest. Anim., 45(6): e249-54.

27. Herrid, M., Vignarajan, S., Davey, R., Dobrinski, I. and Hill, J.R. (2006) Successful transplantation of bovine testicular cells to heterologous recipients. Reproduction, 132(4): 617-624.

28. Herrid, M., Davey, R., Stockwell, S., Olejnik, J., Schmoelzl, S., Suchowerska, N., Jackson, M., Holland, M. and Hill, J.R. (2011) A shorter interval between irradiation of recipient testis and germ cell transplantation is detrimental to recovery of fertility in rams. Int. J. Androl., 34(5): 501-512.

29. Bahadorani, M., Hosseini, S.M., Abedi, P., Hajian, M., Hosseini, S.E., Vahdati, A., Baharvand, H. and NasrEsfahani, M.H. (2012) Short-term in-vitro culture of goat enriched spermatogonial stem cells using different serum concentrations. J. Assist. Reprod. Genet., 29(1): 39-46.

30. Tajik, P., Pajooh, K.H., Elahi, Z.F., Shahedin, G.J. and Ghasemzadeh-Nava, H. (2017) Transfection of bovine spermatogonial stem cells in vitro. Iran. J. Vet. Res., 18(2): 113-118.
31. McMillan, M.E., Schmoelzl, S., Hinch, G. and Andronicos, N. (2013) Towards in vitro Produced Germline Stem Cells in the Bovine. Thesis submitted to University of New England, Australia.

32. Borjigin, U., Yun, T., Herrid, M. and Bou, S. (2012) Characterization and isolation of ovine spermatogonial stem cells. J. Anim. Vet. Adv., 11(8): 1242-1245.

33. Zhang, P., Li, F., Zhang, L., Lei, P., Zheng, Y. and Zeng, W. (2020) Stage-specific embryonic antigen 4 is a membrane marker for enrichment of porcine spermatogonial stem cells. Andrology, 8(6): 1923-1934.

34. Wu, J., Song, W., Zhu, H., Niu, Z., Mu, H., Lei, A., Yang, C., Peng, S., Li, X., Li, G. and Hua, J. (2013) Enrichment and characterization of Thy1-positive male germline stem cells (mGSCs) from dairy goat (Capra hircus) testis using magnetic microbeads. Theriogenology, 80(9): 1052-1060.

35. Wang, J., Cao, H., Xue, X., Fan, C., Fang, F., Zhou, J., Zhang, Y. and Zhang, X. (2014) Effect of vitamin C on growth of caprine spermatogonial stem cells in vitro. Theriogenology, 81(4): 545-555.

36. Niu, Z., Zheng, L., Wu, S., Mu, H., Ma, F., Song, W., Zhu, H., Wu, J., He, X. and Hua, J. (2015) Ras/ERK1/2 pathway regulates the self-renewal of dairy goat spermatogonia stem cells. Reproduction, 149(5): 445-452.

37. Reding, S.C., Stepnoski, A.L., Cloninger, E.W. and Oatley, J.M. (2010) THY1 is a conserved marker of undifferentiated spermatogonia in the pre-pubertal bull testis. Reproduction, 139(5): 893-903.

38. Cai, H., Tang, B., Wu, J.Y., Zhao, X.X., Wang, Z.Z., An, X.L., Lai, L.X., Li, Z.Y. and Zhang, X.M. (2016) Enrichment and in vitro features of the putative gonocytes from cryopreserved testicular tissue of neonatal bulls. Andrology, 4(6): 1150-1158.

39. Anglin, E., Davey, R., Herrid, M., Hope, S., Kurkuri, M., Pasic, P., Hor, M., Fenech, M., Thissen, H. and Voelcker, N.H. (2010) Cell microarrays for the screening of factors that allow the enrichment of bovine testicular cells. Cytometry A, 77(9): 881-889.

40. Lee, W.Y., Do, J.T., Park, C., Kim, J.H., Chung, H.J., Kim, K.W., Gil, C.H., Kim, N.H. and Song, H. (2016) Identification of putative biomarkers for the early stage of porcine spermatogonial stem cells using next-generation sequencing. PLoS One, 11(1): e0147298.

41. Lee, Y.A., Kim, Y.H., Ha, S.J., Kim, K.J., Kim, B.J., Kim, B.G., Choi, S.H., Kim, I.C., Schmidt, J.A. and Ryu, B.Y. (2014) Cryopreservation of porcine spermatogonial stem cells by slow-freezing testis tissue in trehalose. $J$. Anim. Sci., 92(3): 984-995.

42. Abbasi, H., Tahmoorespur, M., Hosseini, S.M., Nasiri, Z., Bahadorani, M., Hajian, M., Nasiri, M.R. and NasrEsfahani, M.H. (2013) THY1 as a reliable marker for enrichment of undifferentiated spermatogonia in the goat. Theriogenology, 80(8): 923-932.

43. Ren, F., Fang, Q., Xi, H., Feng, T., Wang, L. and Hu, J. (2020) Platelet-derived growth factor-BB and epidermal growth factor promote dairy goat spermatogonial stem cells proliferation via Ras/ERK1/2 signaling pathway. Theriogenology, 155: 205-212.

44. Zhu, H., Zheng, L., Wang, L., Tang, F., Arisha, A.H., Zhou, H. and Hua, J. (2020) p53 inhibits the proliferation of male germline stem cells from dairy goat cultured on polyL-lysine. Reprod. Domest. Anim., 55(3): 405-417

45. Giassetti, M., de Barros, F., Worst, R., Saurin, G., Bruno, A. and Visintin, J. (2016) Comparison of differential plating methods to isolate bovine spermatogonial stem cells. Reprod. Domest. Anim., 51(1): 26-32.

46. Nasiri, Z., Hosseini, S.M., Hajian, M., Abedi, P., Bahadorani, M., Baharvand, H. and Nasr-Esfahani, M.H. (2012) Effects of different feeder layers on short-term culture of prepubertal bovine testicular germ cells in-vitro. Theriogenology, 77(8): 1519-1528.

47. Youssefi, R., Tajik, P., Movahedin, M. and Akbarinejad, V. 
(2016) Enhancement in colonization of bovine spermatogonial stem cells following addition of knock-out serum replacement to culture medium. Vet. Res. Forum, 7(4): 275-280.

48. Giassetti, M.I., Goissis, M.D., de Barros, F.R.O., Bruno, A.H., Assumpção, M.E.O. and Visintin, J.A. (2016) Comparison of diverse differential plating methods to enrich bovine spermatogonial cells. Reprod. Domest. Anim., 51(1): 26-32.

49. Kim, K.J., Lee, Y.A., Kim, B.J., Kim, Y.H., Kim, B.G., Kang, H.G., Jung, S.E., Choi, S.H., Schmidt, J.A. and Ryu, B.Y. (2015) Cryopreservation of putative prepubertal bovine spermatogonial stem cells by slow freezing. Cryobiology, 70(2): 175-183.

50. De Barros, F.R.O., Worst, R.A., Saurin, G.C.P., Mendes, C.M., Assumpção, M.E.O. and Visintin, J.A. (2012) $\alpha-6$ integrin expression in bovine spermatogonial cells purified by discontinuous percoll density gradient. Reprod. Domest. Anim., 47(6): 887-890.

51. Herrid, M., Davey, R.J. and Hill, J.R. (2007) Characterization of germ cells from prepubertal bull calves in preparation for germ cell transplantation. Cell Tissue Res., 330(2): 321-329.

52. Redden, E., Davey, R., Borjigin, U., Hutton, K., Hinch, G., Hope, S., Hill, J. and Herrid, M. (2009) Large quantity cryopreservation of bovine testicular cells and its effect on enrichment of Type A spermatogonia. Cryobiology, 58(2): 190-195.

53. Pan, C., Yu, S., Zhang, P., Wang, B., Zhu, Z., Liu, Y. and Zeng, W.X. (2017) Effect of sucrose on cryopreservation of pig spermatogonial stem cells. J. Integr. Agric., 16(5): 1120-1129.

54. Moghaddam, A.A., Rahimi-Feyli, P., Nikousefat, Z. and Zarghami, S. (2016) Effects of different concentrations of sucrose and fetal bovine serum on viability rate of lamb spermatogonial stem cells before and after cryopreservation. Feyz J. Kashan Univ. Med. Sci., 20(2): 157-164.

55. Zandi, A., Rahimi-Feyli, P. and Moghaddam, A.A. (2016) Effect of testosterone on ovine spermatogonial colony formation in-vitro. Feyz J. Kashan Univ. Med. Sci., 20(3): 205-213.

56. Rodriguez-Sosa, J.R., Dobson, H. and Hahnel, A. (2006) Isolation and transplantation of spermatogonia in sheep. Theriogenology, 66(9): 2091-2103.

57. Luo, J., Megee, S. and Dobrinski, I. (2009) Asymmetric distribution of UCH-L1 in spermatogonia is associated with maintenance and differentiation of spermatogonial stem cells. J. Cell Physiol., 220(2): 460-468.

58. Luo, J., Megee, S., Rathi, R. and Dobrinski, I. (2006) Protein gene product 9.5 is a spermatogonia-specific marker in the pig testis: Application to enrichment and culture of porcine spermatogonia. Mol. Reprod. Dev., 73(12): 1531-1540.

59. Shirazi, M.S., Heidari, B., Naderi, M.M., Behzadi, B., Sarvari, A., Borjian-Boroujeni, S., Farab, M. and Shirazi, A. (2015) Transplantation of goat spermatogonial stem cells into the mouse rete testis. Int. J. Anim. Biol., 1(3): 61-68.

60. Heidari, B., Rahmati-Ahmadabadi, M., Akhondi, M.M., Zarnani, A.H., Jeddi-Tehrani, M., Shirazi, A., Naderi, M.M. and Behzadi, B. (2012) Isolation, identification, and culture of goat spermatogonial stem cells using c-kit and PGP9.5 markers. J. Assist. Reprod. Genet., 29(10): 1029-1038.

61. Shirazi, M.S., Heidari, B., Shirazi, A., Zarnani, A.H., JeddiTehrani, M., Rahmati-Ahmadabadi, M., Naderi, M.M., Behzadi, B., Farab, M., Sarvari, A., Borjian-Boroujeni, S. and Akhondi, M.M. (2014) Morphologic and proliferative characteristics of goat Type A spermatogonia in the presence of different sets of growth factors. J. Assist. Reprod. Genet., 31(11): 1519-1531.

62. Heidari, B., Gifani, M., Shirazi, A., Zarnani, A.H., Baradaran, B., Naderi, M.M., Behzadi, B., BorjianBoroujeni, S., Sarvari, A., Lakpour, N. and Akhondi, M.M. (2014) Enrichment of undifferentiated Type A spermatogonia from goat testis using discontinuous percoll density gradient and differential plating. Avicenna J. Med. Biotechnol., 6(2): 94-103.

63. Shafiei, S.H, Tajik, P.1, Ghasemzadeh Nava, H.1, Movahedin M., Talebkhan Garoussi, M.1, Qasemi Panahi, B. and Rahimi Feyli P. (2013) Isolation of bovine spermatogonial cells and co-culture with prepubertal sertoli cells in the presence of colony-stimulating factor-1. Iran. J. Vet. Med., 7(2): 83-90.

64. Jabarpour, M. and Tajik, P. (2017) Evaluation of the effect of follicular stimulating hormone on the in vitro bovine spermatogonial stem cells self-renewal: An experimental study. Int. J. Reprod. Biomed., 15(12): 795-802.

65. Qasemi-Panahi, B., Movahedin, M., Moghaddam, G., Tajik, P., Koruji, M., Ashrafi-Helan, J. and Rafat, S.A. (2018) Isolation and proliferation of spermatogonial cells from Ghezel sheep. Avicenna J. Med. Biotechnol., 10(2): 93-97.

66. Herrid, M., Davey, R.J., Hutton, K., Colditz, I.G. and Hill, J.R. (2009) A comparison of methods for preparing enriched populations of bovine spermatogonia. Reprod. Fertil. Dev., 21(3): 393-399.

67. Rasouli, M.H., Zandi, M., Sadeghi, A.A. and EmamjomehKashan, N. (2020) Spermatogonial stem cell survival in ram lambs following busulfan treatment. Anim. Reprod., 17(2): e20200001.

68. Cai, H., Wu, J.Y., An, X.L., Zhao, X.X., Wang, Z.Z., Tang, B., Yue, Z.P., Li, Z.Y. and Zhang, X.M. (2016) Enrichment and culture of spermatogonia from cryopreserved adult bovine testis tissue. Anim. Reprod. Sci., 166: 109-115.

69. Kaul, G., Kumar, S. and Kumari, S. (2012) Enrichment of CD9+ spermatogonial stem cells from goat (Capra aegagrus hircus) testis using magnetic microbeads. Stem Cell Discov., 2(3): 92-99.

70. Dirami, G., Ravindranath, N., Jia, M.C. and Dym, M. (2013) Isolation and culture of immature Rat Type A spermatogonial stem cells: In: Hansson, V., Levy, F.O. and Tasken, K., Editors. Signal Transduction in Testicular Cells: Basic and Clinical Aspects. Vol. 2. Springer, Verlag, Berlin, Germany p141-165.

71. Wu, J., Liao, M., Zhu, H., Kang, K., Mu, H., Song, W., Niu, Z., He, X., Bai, C., Li, G., Li, X. and Hua, J. (2014) Research Article CD49f-positive testicular cells in Saanen dairy goat were identified as spermatogonia. J. Cell Biochem., 115(10): 1712-1723.

72. Herrid, M., Nagy, P., Juhasz, J., Morrell, J.M., Billah, M., Khazanehdari, K. and Skidmore, J.A. (2019) Donor sperm production in heterologous recipients by testis germ cell transplantation in the dromedary camel. Reprod. Fertil. Dev., 31(3): 538-546.

73. Rodriguez-Sosa, J.R., Silvertown, J.D., Foster, R.A., Medin, J.A. and Hahnel, A. (2009) Transduction and transplantation of spermatogonia into the testis of ram lambs through the extra-testicular rete. Reprod. Domest. Anim., 44(4): 612-620.

74. Honaramooz, A., Behboodi, E., Megee, S.O., Overton, S.A., Galantino-Homer, H., Echelard, Y. and Dobrinski, I. (2003) Fertility and germline transmission of donor haplotype following germ cell transplantation in immunocompetent goats. Biol. Reprod., 69(4): 1260-1264.

75. Zeng, W., Tang, L., Bondareva, A., Honaramooz, A., Tanco, V., Dores, C., Megee, S., Modelski, M., Rodriguez-Sosa, J.R., Paczkowski, M., Silva, E., Wheeler, M., Krisher, R.L. and Dobrinski, I. (2013) Viral transduction of male germline stem cells results in transgene transmission after germ cell transplantation in pigs. Biol. Reprod., 88(1): 27.

76. Cai, Y., Deng, M., Liu, Z., Zhang, G., Pang, J., An, S., Wang, Z., Zhang, Y. and Wang, F. (2020) EZH2 expression and its role in spermatogonial stem cell self-renewal in goats. Theriogenology, 155: 222-231.

77. Zeng, W., Tang, L., Bondareva, A., Luo, J., Megee, S.O., Modelski, M., Blash, S., Melican, D.T., Destrempes, M.M., Overton, S.A., Gavin, W.G., Ayres, S., Echelard, Y. and 
Dobrinski, I. (2012) Non-viral transfection of goat germline stem cells by nucleofection results in production of transgenic sperm after germ cell transplantation. Mol. Reprod. Dev., 79(4): 255-261.

78. Park, K., Kim, M.S., Kang, M., Kang, T., Kim, B. and Lee, S.T. (2019) Successful genetic modification of porcine spermatogonial stem cells via an electrically responsive $\mathrm{Au}$ nanowire injector. Biomaterials, 193: 22-29.

79. Honaramooz, A., Megee, S.O. and Dobrinski, I. (2002) Germ cell transplantation in pigs. Biol. Reprod., 66(1): 21-28.

80. Honaramooz, A., Behboodi, E., Blash, S., Megee, S.O. and Dobrinski, I. (2003) Germ cell transplantation in goats. Mol. Reprod. Dev., 64(4): 422-428.

81. Izadyar, F., Den Ouden, K., Stout, T.A.E., Stout, J., Coret, J., Lankveld, D.P.K., Spoormakers, T.J.P., Colenbrander, B., Oldenbroek, J.K., Van der Ploeg, K.D., Woelders, H., Kal, H.B. and De Rooij, D.G. (2003) Autologous and homologous transplantation of bovine spermatogonial stem cells. Reproduction, 126(6): 765-774.

82. Stockwell, S., Herrid, M., Davey, R., Brownlee, A., Hutton, K. and Hill, J.R. (2009) Microsatellite detection of donor-derived sperm DNA following germ cell transplantation in cattle. Reprod. Fertil. Dev., 21(3): 462-468.

83. Stockwell, S., Hill, J.R., Davey, R., Herrid, M. and Lehnert, S.A. (2013) Transplanted germ cells persist long-term in irradiated ram testes. Anim. Reprod. Sci., 142(3-4): 137-140.

84. Mikkola, M., Sironen, A., Kopp, C., Taponen, J., Sukura, A., Vilkki, J., Katila, T. and Andersson, M. (2006) Transplantation of normal boar testicular cells resulted in complete focal spermatogenesis in a boar affected by the immotile short-tail sperm defect. Reprod. Domest. Anim., 41(2): 124-128.

85. Joerg, H., Janett, F., Schlatt, S., Mueller, S., Graphodatskaya, D., Suwattana, D., Asai, M. and Stranzinger, G. (2003) Germ cell transplantation in an azoospermic klinefelter bull. Biol. Reprod., 69(6): 1940-1944.

86. Herrid, M., Olejnik, J., Jackson, M., Suchowerska, N., Stockwell, S., Davey, R., Hutton, K., Hope, S. and Hill, J.R. (2009) Irradiation enhances the efficiency of testicular germ cell transplantation in sheep. Biol. Reprod., 81(5): 898-905.

87. Oatley, J.M., de Avila, D.M., Reeves, J.J. and McLean, D.J. (2004) Testis tissue explant culture supports survival and proliferation of bovine spermatogonial stem cells. Biol. Reprod., 70(3): 625-631.
88. Park, K.E., Kaucher, A.V., Powell, A., Waqas, M.S., Sandmaier, S.E.S., Oatley, M.J., Park, C.H., Tibary, A., Donovan, D.M., Blomberg, L.A., Lillico, S.G., Whitelaw, C.B.A., Mileham, A., Telugu, B.P. and Oatley, J.M. (2017) Generation of germline ablated male pigs by CRISPR/Cas9 editing of the NANOS2 gene. Sci. Rep., 7(1): 40176.

89. Bahadorani, M., Hosseini, S.M., Abedi, P., Abbasi, H. and Nasr-Esfahani, M.H. (2015) Glial cell line-derived neurotrophic factor in combination with insulin-like growth factor 1 and basic fibroblast growth factor promotes in vitro culture of goat spermatogonial stem cells. Growth Factors, 33(3): 181-191.

90. Lord, T. and Oatley, J.M. (2017) Regulation of spermatogonial stem cell maintenance and self-renewal. In: The Biology of Mammalian Spermatogonia. Springer, Berlin, Heidelberg. p91-129.

91. Giassetti, M.I., Ciccarelli, M. and Oatley, J.M. (2019) Spermatogonial stem cell transplantation: Insights and outlook for domestic animals. Annu. Rev. Anim. Biosci., 7(1): 385-401.

92. Zhang, P., Chen, X., Zheng, Y., Zhu, J., Qin, Y., Lv, Y. and Zeng, W. (2017) Long-term propagation of porcine undifferentiated spermatogonia. Stem Cells Dev., 26(15): 1121-1131.

93. Zhang, X.M. (2020) GFR $\alpha-1$ is a reliable marker of bovine gonocytes/undifferentiated spermatogonia: A mini-review. Anat. Histol. Embryol., 50(1): 13-14.

94. Kubota, H. and Brinster, R.L. (2017) Transplantation and culture of spermatogonial stem cells. In: The Biology of Mammalian Spermatogonia. Springer, Berlin, Heidelberg. p271-300.

95. Herrid, M., Davey, R., Stockwell, S., Schmoelzl, S., Uphill, G., Poirier, V., Hope, M., Hill, J.R., Holland, M.K. and Lehnert, S.A. (2013) Depletion of testis cell populations in prepubertal Bos indicus cattle by irradiation. Anim. Reprod. Sci., 141(3-4): 124-130.

96. Kim, B.J., Kim, Y.H., Oh, M.G., Kim, K.J., Jung, S.E., Jin, J.H., Kim, S.U., Min, K.S. and Ryu, B.Y. (2019) Direct modification of spermatogonial stem cells using lentivirus vectors in vivo leads to efficient generation of transgenic rats. Asian J. Androl., 21(2): 190-195.

97. Murta, D.V.F., Costa, D.S., Santos, M.D. and Faria, F.J.C. (2010) Somatic and germ cell proliferation during post-natal development of the testis in the wild boar (Sus scrofa scrofa). Anim. Reprod. Sci., 119(1-2): 154-159. 